\title{
Knowledge of Physical Activity Guidelines and Mental Health Benefits among Emirati University Students.
}

Physical activity declines markedly from late adolescence to early adulthood, ${ }^{1}$ which includes the time spent at university. Investigating university students' understanding of physical activity may, therefore, have important implications for promoting an active lifestyle in the population. A study with Chinese university students identified a positive association between awareness of physical activity guidelines and participation in physical activity. ${ }^{2}$ However, in that study only $4 \%$ of Chinese university students could report a recommended guideline for physical activity. ${ }^{2}$ The World Health Organisation (WHO) recommend adults do at least 150 minutes per week of moderate intensity aerobic physical activity, or at least 75 minutes of vigorous intensity aerobic physical activity, throughout the week or an equivalent combination of moderate and vigorous intensity activities. It is also recommended that muscle strengthening activities involving the major muscle groups be performed at least twice a week. ${ }^{3}$

A large study $(n=16,483)$ of European university students identified that students had a strong belief in the association between physical activity and general physical health benefits. ${ }^{4}$ However, there has been limited research to assess university students' beliefs in the association between physical activity and mental health benefits. As the prevalence of mental health problems is significantly higher in university students than in their peers in the general population, ${ }^{5}$ it could be important to understand university students' perceptions about physical activity and mental health.

The current study aimed to assess knowledge of physical activity guidelines and mental health benefits among Emirati university students. Due to well documented gender differences in 
physical activity participation, ${ }^{6}$ and mental health ${ }^{7}$ in university students, differences in knowledge of guidelines and perceived mental health benefits were also explored by gender.

\section{Method}

Participants were recruited from a Higher Education Institute in the Middle East. A stratified (by gender) random sample ( $\mathrm{n}=1462 ; 50 \%$ female) was derived from the university database, and emailed the online survey invitation which included a participant information sheet and consent form. The online survey remained open for responses for two weeks and all those invited received up to three reminder prompts by email. Participants were asked "what is the recommended amount of moderate to vigorous physical activity for adults to do each week for good health" with a free response provided in mins/week. Reflecting WHO guidelines for physical activity for adults ${ }^{3}$, the amount of time reported by respondents was classified as: 150-300 mins/week; overestimated ( $>300 \mathrm{mins} /$ week); and underestimated $(<150 \mathrm{mins} /$ week $)$ guideline. Participants were also asked to rate to what extent exercise can help to: improve wellbeing, manage depression, and manage anxiety/stress. Responses were indicated on a 5 point Likert scale with anchor ratings $(1=$ not at all; $5=$ very much $)$, and collapsed into 2 categories $(1-3=$ low, 4-5 = high). Participants completed demographic items on age, gender, height, weight, living situation, and if they had children.

All data were exported into IBM SPSS Statistics for Windows Version 24. Ten percent of the data entered was checked for accuracy and no errors were found. Descriptive statistics were reported for knowledge of physical activity guidelines and perceived mental health benefits. Participants responses for knowledge of guidelines were dichotomised into 150-300 mins/week, over-estimated (>300 mins/week), and under-estimated $(<150 \mathrm{mins} /$ week $)$. Participant responses for mental health benefits were dichotomised into low (1-3) and high (4- 
5). Gender differences for knowledge of guidelines and mental health benefits were explored using binary logistic regressions, adjusting for body mass index (BMI) and age.

\section{Results}

Of the 1462 students invited to participate in the study, 628 completed the questionnaire (response rate 43\%). Participant characteristics and results for knowledge of physical activity guidelines and benefits of physical activity for mental health are presented in Table 1. Only $3 \%$ of respondents identified $150 \mathrm{mins} / \mathrm{week}$, and $39 \%$ of respondents reported a value between 150-300 mins/week. Over two thirds (69\%) of the sample reported high scores for the extent to which exercise could help improve wellbeing, and just under three quarters reported high scores for the extent to which exercise could help manage depression (71\%) and anxiety/stress (74\%). Females were significantly more likely than males to report high scores for extent to which exercise could help manage depression $(\mathrm{OR}=1.8 ; 95 \% \mathrm{CI}=1.2-2.6 ; \mathrm{p}=0.003)$ and anxiety/stress $(\mathrm{OR}=1.8 ; 95 \% \mathrm{CI}=1.2-2.7 ; \mathrm{p}=0.002)$, having adjusted for BMI, and age. There were no other gender differences in knowledge of activity guidelines or for exercise to improve wellbeing.

\section{TABLE 1 NEAR HERE}

\section{Discussion}

Knowledge of physical activity guidelines is important if people are to participate in an appropriate amount to achieve health benefits. In the current study, knowledge of physical activity guidelines was very low with $3 \%$ identifying 150 mins/week and 39\% identifying a value between 150-300 mins/week. Rates of agreement for the $150 \mathrm{mins} /$ week amount in the current study were similar to other research with Chinese university students, ${ }^{2}$ and much lower 
than another study with American university students. ${ }^{8}$ This variation could be due to differences in survey design as both the current study and the study with Chinese university students $^{2}$ utilised a free response but the American study asked respondents to choose from four possible response options. No gender differences were found for knowledge of guidelines and this is similar to research in American university students. ${ }^{8}$

Promoting awareness of the recommended amount of physical activity could be particularly important for those who overestimated (22\%) and underestimated $(38 \%)$ the guideline. Increasing awareness of guidelines in those who over-estimated may reduce the perceived time burden associated with participation. Lack of time is frequently cited as a major barrier to activity, and availability of free time has been identified as an enabler of physical activity in university students. ${ }^{9}$ Strategies may also be required to promote awareness in those who underestimated guidelines as their current levels of participation may not be sufficient to realise health benefits.

Past research with public health managers in Oman identified the perception that Arab people had a low awareness of the benefits of physical activity. ${ }^{10}$ Our results found that a majority of Arab university student participants believed that physical activity could improve mental health. Females were more likely than males to report high scores for the extent to which physical activity could help manage depression, anxiety, and stress. It may be that as females are more vulnerable to poor mental health such as depression and anxiety, ${ }^{7}$ they have a greater awareness of self-management strategies, such as physical activity. More research may be required in this population to understand the reason for these gender differences. 
A limitation of the current study is that students were asked to report on the recommended amount of moderate to vigorous physical activity. However, physical activity guidelines recommend at least $150 \mathrm{mins} /$ week moderate physical activity and $75 \mathrm{mins} /$ week vigorous physical activity and it is possible that some people may have had difficulty in reporting a recommended amount of moderate to vigorous physical activity. Another limitation is the response rate $(43 \%)$ was relatively low, however low response rates have previously been reported in other research with university student populations. ${ }^{5,7}$

The results of this study suggest that more work may be required to promote awareness of physical activity guidelines, and males' awareness of mental health benefits of physical activity, in Emirati university students. The university campus could be an ideal environment to increase awareness of physical activity guidelines due to availability of physical activity facilities and staff to promote physical activity. Increased awareness about the benefit of physical activity for managing depression, anxiety and stress may also help reduce the high prevalence of poor mental health typically reported among university students. Increasing awareness of physical activity guidelines and mental health benefits may lead to increased participation and associated health and wellbeing benefits for students during their time at university and across the adult life course.

\section{Ethics}

The research was approved by The University of Queensland Human Research Ethics Committee (2017000527).

\section{Funding}

This research received no specific grant from any funding agency in the public, commercial, or not-for-profit sectors. 


\section{Conflict of interest}

The authors declare that there is no conflict of interest. 


\section{References}

1. Kwan MY, Cairney J, Faulkner GE, et al. Physical activity and other health-risk behaviors during the transition into early adulthood: a longitudinal cohort study. American Journal of Preventive Medicine 2012; 42: 14-20. 2011/12/20. DOI: 10.1016/j.amepre.2011.08.026.

2. Abula K, Gröpel P, Chen K, et al. Does knowledge of physical activity recommendations increase physical activity among Chinese college students? Empirical investigations based on the transtheoretical model. Journal of Sport and Health Science 2018; 7: 77-82. DOI: 10.1016/j.jshs.2016.10.010.

3. World Health Organization. Prevalence of insufficient physical activity, http://www.who.int/gho/ncd/risk factors/physical activity text/en/ (2010).

4. Steptoe A, Wardle J, Cui W, et al. Trends in smoking, diet, physical exercise, and attitudes toward health in European university students from 13 countries, 1990-2000. Prev Med 2002; 35: 97-104. 2002/08/30.

5. Stallman HM. Psychological distress in university students: A comparison with general population data. Australian Psychologist 2010; 45: 249-257. DOI:

10.1080/00050067.2010.482109.

6. Keating XD, Guan J, Piñero JC, et al. A meta-analysis of college students physical activity behaviors. Journal of American College Health 2005; 54: 116-126. DOI: 10.3200/JACH.54.2.116-126.

7. Ridner SL, Newton KS, Staten RR, et al. Predictors of well-being among college students. Journal of American College Health 2016; 64: 116-124. DOI: 10.1080/07448481.2015.1085057.

8. McArthur LH and Raedeke TD. Race and sex differences in college student physical activity correlates. American Journal of Health Behavior 2009; 33: 80-90. DOI: 10.5993/AJHB.33.1.8.

9. Deliens T, Deforche B, De Bourdeaudhuij I, et al. Determinants of physical activity and sedentary behaviour in university students: A qualitative study using focus group discussions. BMC Public Health 2015; 15: 201. DOI: 10.1186/s12889-015-1553-4.

10. Mabry RM, Al-Busaidi ZQ, Reeves MM, et al. Addressing physical inactivity in Omani adults: perceptions of public health managers. Public Health Nutrition 2014; 17: 674-681.

DOI: $10.1017 /$ S1368980012005678. 
Table 1 Knowledge of physical activity guidelines and mental health benefits among Emirati university students $(n=628)$

\begin{tabular}{|c|c|c|c|}
\hline Characteristics & $\begin{array}{l}\text { All } \\
\%\end{array}$ & $\begin{array}{c}\text { Female } \\
\%\end{array}$ & $\begin{array}{c}\text { Male } \\
\%\end{array}$ \\
\hline Total & & 69.1 & 30.9 \\
\hline \multicolumn{4}{|l|}{ Age group (years) } \\
\hline $18-20$ & & 58.3 & 56.2 \\
\hline $21-24$ & & 35.2 & 32.5 \\
\hline $25+$ & & 6.5 & 11.3 \\
\hline \multicolumn{4}{|c|}{ Self-reported body mass index $(\mathrm{kg} / \mathrm{m} 2)$} \\
\hline Underweight $(<18.5)$ & & 14.7 & 7.2 \\
\hline Healthy (18-24.9) & & 52.1 & 37.6 \\
\hline Overweight (25-29.9) & & 15.9 & 28.9 \\
\hline Obese $(30+)$ & & 17.3 & 26.3 \\
\hline \multicolumn{4}{|l|}{ Living situation } \\
\hline Single and live alone & & 0.5 & 3.6 \\
\hline Single and live with family & & 87.3 & 88.7 \\
\hline Married and live with partner & & 8.7 & 6.2 \\
\hline Other & & 3.5 & 1.5 \\
\hline \multicolumn{4}{|l|}{ Children } \\
\hline Yes & & 5.1 & 6.2 \\
\hline No & & 94.9 & 93.8 \\
\hline \multicolumn{4}{|c|}{ Knowledge of physical activity guideline } \\
\hline Underestimated $(<150 \mathrm{mins} / \mathrm{week})$ & 38.4 & 41.0 & 32.4 \\
\hline $150-300 \mathrm{mins} /$ week & 39.2 & 39.4 & 38.7 \\
\hline Overestimated (>300 mins/week) & 22.4 & 19.6 & 28.9 \\
\hline \multicolumn{4}{|l|}{$\begin{array}{l}\text { Extent to which exercise can help } \\
\text { improve wellbeing }\end{array}$} \\
\hline High (4-5) & 69.4 & 68.0 & 72.7 \\
\hline Low (1-3) & 30.6 & 32.0 & 27.3 \\
\hline \multicolumn{4}{|l|}{$\begin{array}{l}\text { Extent to which exercise can help to } \\
\text { manage depression }\end{array}$} \\
\hline High (4-5) & 71.4 & 74.9 & 63.4 \\
\hline Low (1-3) & 28.6 & 25.1 & 36.4 \\
\hline \multicolumn{4}{|l|}{$\begin{array}{l}\text { Extent to which exercise can help to } \\
\text { manage stress/anxiety }\end{array}$} \\
\hline High $(4-5)$ & 73.6 & 77.0 & 66.0 \\
\hline Low (1-3) & 26.4 & 23.0 & 34.0 \\
\hline
\end{tabular}

